\title{
Critical Thinking in Gifted Children's Offline and Online Peer Feedback
}

\author{
Myriah T. Miller \& Jill Olthouse \\ West Virginia University, United States
}

\begin{abstract}
This comparative study identified the differences between gifted children's offline and online peer feedback within a summer talented writer's workshop. Researchers analyzed ten students' writings for degrees of critical thinking evident in their feedback. Online feedback included students' writings in social writing sites Storybird.com and KidBlog. Offline feedback was submitted on a teacher designed rubric, and then incorporated into a revised manuscript using Microsoft Word. Critical thinking was defined as the three upper tiers of Bloom's Taxonomy: analysis, and evaluation, and synthesis. Each comment in students' online and offline feedback was coded according to one of the levels of Bloom's Taxonomy. In addition, interpretative summaries were written describing how students used feedback within each category. Results indicated that critical thinking (specifically analysis and evaluation) was more evident in the responses that were structured opposed to those that were in the social media contexts. There was also evidence of an increased amount of informal dialogue in the online feedback opposed to the structured feedback. Online writing technologies are seen to be most successful when teachers' expectations for critical thinking and students' desire for informal positive feedback are combined; this success depends on the presence of a skilled teacher and supportive peers, rather than on the presence of a specific technology tool.
\end{abstract}

Keywords: Critical thinking; Educational technology; Peer feedback; Bloom's Taxonomy; Gifted Students; Social Media; Writing

\section{Introduction}

This study used both qualitative and quantitative analysis to examine gifted children's use of educational technology, peer feedback, and critical thinking. The $21^{\text {st }}$ century classroom embraces educational technology use with writing as the $18^{\text {th }}$ century classroom did with quill and ink. Unlike students of the past, students today are able to publish their work for immediate viewing allowing feedback to play as an open dialogue between authors and readers. This article will explore the role of educational technology and peer feedback in gifted children's writing process. The purpose of the study is to compare and contrast gifted children's use of critical thinking in two situations: while giving peer feedback using a structured paper guide and while giving peer feedback using online social commenting on blogging and digital storytelling websites.

Today's literacy not only includes the traditional emphasis on comprehension and writing, but has expanded to include multiliteracies (Schoffner, Oliveira, \& Angus, 2010). Multiliteracies, a term 
coined by The New London Group, redefined the traditional literacy definition. Literacy has broadened to include various formal and informal expressions and communications whether spoken, gestured, written or graphic (Katsarou, 2009). Educational technology is just one strand of multiliteracies. However, it is a primary experience for young scholars as opposed to their predecessors who were introduced to everyday uses of educational technology in adulthood. Prensky (2001) referred to these young scholars as digital natives, since they have grown up with these new technologies and the secondary learners as digital immigrants. In fact, a study by Rideout, Foehr, and Roberts (2010) indicated that students are spending over 75 hours a week using certain technologies to watch movies or videos, listening to music, and using the internet or playing video games. This is the normalcy of their lives, thus this is where a majority of their literacy is enacted.

According to multiliteracies theory, the purpose of literacy is to design social futures. "Design" is a type of higher order thinking, similar to synthesis and creativity (Bloom et al, 1956). In the revised version of Bloom's Taxonomy, creating is now higher than evaluating (Krathowl, 2002). When students learn to evaluate existing writings, they begin to see the potential for new directions. According to multiliteracies theory, design means more than making a product, and it involves shaping social contexts and reimagining possible futures. In addition, designing a written product becomes multimodal, digital, and in some cases multilingual. The New London group (1996) asserts, "The notion of design connects powerfully to the sort of creative intelligence the best practitioners need in order to be able, continually, to redesign their activities in the very act of practice." Literate students must be able to do more than follow a formula or write to a prompt. They must use design knowledge to critique and create texts for social purposes. Creativity in the current economy often includes collaboration using social writing technologies such as wikis or Facebook. Collaboration allows young writers to work together in a manner similar to the way professional authors work with peers and editors (Yagelski, 1995).

\section{Literature Review}

\section{Writing Technologies}

Since the computer allowed writers to more efficiently make changes to their texts, educational technology has been rapidly changing writing instruction. In the study, children used three main technologies as tools to aid their writing. One of these technologies, word processing, was one that the children only occasionally used at school. The other technologies, digital storybooks, and blogging were new to most students. The students used web 2.0 technologies that allowed for multimedia writing and online peer feedback via social commenting, sometimes for the first time. Much of the research in the field of computers and composition, especially in regard to web 2.0 technologies is conducted with college students. However, there are many free online writing platforms that offer multimedia, collaboration, and publishing features in a kid-safe environment (Olthouse \& Miller, 2012). Digital storytelling using web 2.0 technologies allows students to coordinate the synthetic relationship of image and text (Yang, 2012), to communicate their knowledge in an original way (Bran, 2010); and to increase writing skills, educational technology skills, and motivation for writing (Drexler, 2007). Microsoft Word allows students to use features such as spell-check, thesaurus, and cut-and paste to easily make revisions to a text. Storybird.com 
is a website where children create picture books using a provided bank of high quality illustrations along with the children's original texts. Kidblog is a website where students can create blogs that are only viewable by their classmates. Though the students in this study primarily used blogs for expository writing, Kidblog also supports embedded pictures, movies, and hyperlinks. Both KidBlog and Storybird allow students to read each other's published works and post comments beneath the work. These comments can be moderated by a teacher before they are posted.

\section{Peer Feedback and Writing Achievement}

Reciprocal peer revision has been shown to improve writing performances of different levels of writers (i.e., MacArthur, Schwartz, \& Graham, 1991; Stoddard \& Mac-Arthur, 1993; Patchan, 2011). Peer revision leads to effective enhancement of writing performances through modeling of enthusiasm, encouragement, motivation, and coping (Yarrow \& Topping, 2001). This processbased writing instruction helps both challenged and skilled writers to move through three different stages of revision: 1 ) detecting problems in a text, 2) diagnosing those problems, and 3) selecting a strategy to deal with those problems. (Flower, Hayes, Carey, Schriver, \& Stratman, 1986). While there have been no studies of gifted children engaged in peer revision, a study of college writers found that while mixed-ability peer revision improved both writers' performance, homogenous groupings were most beneficial for skilled writers (Patchan, 2011). Overall, peer assistance is one of the most effective writing interventions in elementary school (Graham, McKeown, Kiuhare, \& Harris), with an effect size in metanalysis of .89 for peer assistance, and a lower rate (.37) for peer assessment.

Today's writers have both formal and informal writing experiences. When students supply peer feedback in school, they typically provide formal comments that improve upon the written work. Today, students belong to and participate in a variety of social media sites that include Facebook, Twitter, blogs, and many other informal communicative media or digital texts. The feedback provided in these online spaces is less revision oriented than formal feedback might be. Instead they provide opportunities for interpretative and expressive dialogue. Initially, student discussions are more prone to discuss personal stories or descriptive content. However, effective discussions include both reflections on the topic and evidence of critical thinking (Ertmer, Richardson, Bellan, Carmin, \& Connely, 2007).

With expectations and guidance, peer feedback can play an integral aspect in the writing process, both formal and informal. Students become active participants in each other's learning and gain a better understanding for their peer's perspectives (Ertmer et al., 2007). A study by Kaufman, Gentile \& Baer (2005) supported gifted student's participation in peer feedback on creative works. They found that evaluations of creative works were similar between gifted student writers and creative writing experts, indicating the gifted students' capabilities to provide useful feedback.

\section{Gifted Children's Writing and Higher-Level Thinking}

Giftedness is often defined as a capacity for creative or critical thought. Gifted children not only learn rapidly, they are adept at dealing with complexity and abstract concepts. Assignments in 
Gifted Education programs generally focus on the higher levels of Bloom's Taxonomy (analysis, synthesis, and evaluation). Children with writing talent (which may or may not be the same group as identified gifted students) demonstrate higher-level skills in their writing, such as paradox, humor, wisdom, and philosophical or moral themes (Piirto, 2004). It is likely that when giving peer feedback on writing, gifted children should be able to go beyond merely editing for capitalization and spelling, and provide substantial support to their peers.

\section{Methodology}

\section{Participants}

For this study, purposive sampling (Gay, Mill, \& Airasian, 2012) was used to identify possible participants. Participants were gifted children who participated in a 2012 Talented and Gifted (TAG) workshop located on a local university campus. The workshop contained approximately thirty-four incoming third through sixth graders. Entrance requirements of the students included submitting writing samples. Even though maintaining the exceptionality of 'gifted' through their schools was not a requirement, they all participated in TAG programs at their respective schools. The workshop lasted five days and was split into two three hour courses. Of those students attending the workshop, ten students, four boys and six girls, agreed to participate in the study. Informed consent was obtained in person both from the parents and a signed assent form from the student themselves. Confidentiality was a priority within the ethical considerations of the research. Therefore, students' names and any identifying information were replaced with pseudonyms or numbers.

\section{Data Analysis}

The data used in this study included the children's peer feedback in response to creative and expository writing. Students wrote daily Kidblog entries on current events in their journalism class, and they rewrote popular fiction stories from the villian's point of view in their creative writing class. In addition, students in the creative writing class wrote picture books using storybird.com. The Storybird and Kidblog data were combined under the social media or online category, while the peer rubric critiques for the fiction stories were categorized as offline data. Within the Kidblog, 85 comments were analyzed whereas Storybird had 40 comments. This totaled 125 incidences of feedback within the online realm. The peer critique rubrics included 57 peer feedback comments.

Data analysis had two phases. In the first phase, the researcher coded each individual peer feedback comment according to the predetermined categories of bloom's taxonomy. Critical thinking skills are defined as "requiring judgment, analysis, and synthesis; and are not applied in rote or mechanical manner. [Critical thinking] is reflective, sensitive to the context, and selfmonitored" (Halpern, 1998. p.451). In terms of peer feedback in writing, critical thinking scenarios might include the reviewer asking the author "Why is the antagonist apathetic to his doom?" This process requires both parties to analyze the character and reflect on human nature thus, encouraging critical thinking. Another author may be asked to determine appropriate resources 
for an article which requires judgment of reliability and authenticity; whereas, feedback that states "You need quotation marks around when he is speaking" requires a lower level of cognitive functioning. Inserting the rules of grammar does not require critical thinking, but simply a knowledge recall. So, the first author tagged all feedback in a ranking system of 1-6 to represent the six level of Bloom's Taxonomy: 1) knowledge, 2) comprehension, 3) application, 4) analysis, 5)evaluation and 6) synthesis. For this study, critical thinking was acknowledged in the rankings of 4-6. However, much of the data were not appropriately categorized in these levels, so they were housed in an alternate level entitled 'social media lingo.'

The data were analyzed in terms of just identifying the critical thinking skills. For the Villain writing project, the students critiqued each other on a teacher provided, open response rubric. This rubric included the following goals: 1 . Students paper is well organized and is a cohesive paper 2. Student uses appropriate voice and tone in the writing. 3. Student demonstrates original and creative writing and uses imagery, detailed descriptions and figurative language. The peer reviewers determined if the author met these goals and explained why or why not. The reviewers were then to leave a suggestion and a compliment for each goal. These also were highlighted at any incidence of critical thinking. The instances that indicated the upper levels of Bloom's Taxonomy were recorded and coded separate from the online spaces. Since the feedback on Kidblog and Storybird were strictly in an online space, their results were listed separately.. We grouped the results within their correlating categories spanning across the six levels of Bloom's Taxonomy as well as the sub-level social media lingo that was not able to be categorized within the hierarchy's parameters. Secondly, the researchers used collaborative writing and discussion to discuss how each category functioned to go beyond merely counting codes. Finally, we used collaborative discussion and writing to determine overall themes and implications.

\section{Quality Measures}

Both researchers are gifted education teachers who have had Masters' level training and practical experience working with the various levels of Bloom's Taxonomy. Thus, to some extent the researchers were the instrument (Patton, 2002) using their professional judgment to ascertain the level of Bloom's Taxonomy that students demonstrated. In order to address the trustworthiness of the data analysis process, the secondary author (who is also a gifted education teacher) independently coded a portion of the data, and the lead author discussed discrepancies in order to come to consensus about the coding (Baxter \& Jack, 2008). Both authors independently coded $10 \%$ of the data, leading to an initial $73 \%$ agreement in coding. We discussed areas of disagreement, which consistent mostly of differing understandings of analysis and evaluation. We then came to an agreement with the lead author's understanding of evaluation, which was "a statement of judgment or opinion, supported with at least one piece of evidence."

\section{Limitations of the Study}

Many sub-groups were not accounted for in this study such as those gifted students who chose or could not afford to attend a summer workshop or the lack of representation of certain ethnic groups of African-American, Hispanic-American, or Asian-American. Furthermore, because a small 
group of participants was involved, it may be difficult to generalize to other populations. However, a small sample, or case study design allows for in depth analysis. Also, this study is only a glimpse of talented writers' educational technology experiences, especially with peer feedback. To have a better understanding of educational technology's role in fostering critical thinking skills, the focus should extend past feedback alone. In addition, the amount of data from the critique rubrics were less than the online commenting. To better represent social media commenting with teacher guidance, data from an alternate sources or more examples should better correlate to the amount of data without guidance.

\section{Findings}

When educational technology is utilized in the classroom, the question was "How does this educational technology facilitate critical thinking with social commenting and feedback as compared to structured rubrics?" Analysis of the feedback utilized the differing levels of Bloom's Taxonomy as a guide to identifying those critical thinking skills. These levels are progressive or hierarchal and at each increasing level the cognitive functioning needed to demonstrate these skills are also increased.

\section{Level 1: Knowledge}

This level of Bloom's Taxonomy is considered the lowest level as far as measuring the true depth of knowledge of the content. It is simply the recall of information. Examples of key verbs that illustrate the action of this level include defining, naming, or stating. The data illustrated various examples of this level. An entrance activity that the students participated in within the journalism workshop was to read current events on the Smithsonian website and blog about their findings. Within this activity students demonstrated multiple examples of their knowledge. When a student was asked for clarification on a definition of a festival, he responded "It's a festival that celebrates the anivesity of the Smithsonian."(sic) This student demonstrated at the knowledge level he defined the festival. In the same respect, another student was asked about the jellyfish that was in his post. He responded with the definition of "Ocean Sunfish are fish that eat jellyfish." These responses were indicative of the type of questioning that was utilized. The questions were simple recall or naming questions; therefore, their answers leveled that of the questioning requirements. They were not asked or required to produce answers that utilized critical thinking so, their responses did not demonstrate it. They type of questioning directly relates to the level of response that is necessary. Within the social media contexts, the Kidblog and Storybird comments, 17 out of 125 or $13.6 \%$ of responses were identified as being knowledge recall. The more formal feedback of the peer critiques produced 5 out of 57 or $8.7 \%$ of responses being categorized as level one.

Before students can produce at the other levels of the hierarchy, they must have this level mastered. Theoretically, students cannot perform in the upper levels of the tiers if they are not knowledgeable in the respective content. So, even though this is considered the lowest level cognitively it is essentially the foundation that all other levels are built. Students were more likely to demonstrate this knowledge level in their responses where new content was being presented such as with the current events. Student's use of this level is attributed to questioning or wanting 
to find out more of a new topic. They would ask for clarification on a meaning of an unknown word or what the definition of the unknown word is. This type of questioning and the responses that it requires are on the factual and simply ask for recall.

\section{Level 2: Comprehension}

Comprehension, by definition, is the understanding of the content. Within the feedback, the most responses that were categorized under this section were discussion based or restating portions of the content being discussed. Some key verbs that distinguish this level include discussing, predicting, and generalizing.

In the Creative Writing workshop, students were asked to write a story from a villain's or antagonist's perspective that was based on a published book. At one point during the revision process, students were to use a free-response rubric to critique a peer's writing. Comprehension was demonstrated in some of their responses. One student wrote "It is all in the same order as in the original story." This student demonstrated level 2 cognitive functioning because she identified that the order of events between the published book and the creative writer's work were paralleled in sequence or structure. Without understanding the two stories, she would not have been able to make this comparison.

In conjunction with comprehension, a discussion of the content can illustrate this level as well. In this case, students were blogging as if they were the antagonist that they were trying to be sympathetic to in their Villain project. A discussion pursues of the blogger asking "Why am I on trial?" Some of the discussion that occurred included a reader being apologetic to his situation and saying "sorry" while another reader turn the question back to the blogger asking "Hey, what do you think" and another reader chimes in "guilty!" To participate in the discussion, the students would have to have some base knowledge of the original story. Students utilized this type of thinking when the content is being discussed. Their discussions were not thorough and many times did not demonstrate critical thinking, yet the discussions were prominent in the social media feedback. Social media indicated 34 or $27.2 \%$ incidences of comprehension where the peer critiques demonstrated 6 occurrences or $10.5 \%$. They are able to converse with their peers on a surface level without any teacher instruction or intervention. This is probably true due to the nature of their social interactions on informal media. Their discussions in the social settings are very matter of fact which was also true in the social media feedback.

\section{Level 3: Application}

When a student takes what they have learned and applies that to new situations, they are performing at the cognitive level of application. Words such as applying, changing, solving, and completing are how students show their application of content. Little of this was shown in the data simply because of the nature of the research. Even though throughout the workshop, students demonstrated application of learned material, little was identified within the technological feedback on an individualized basis. Application was demonstrated in the students' 
educational technology knowledge to navigate through and create their Storybirds or blogs. This is also true in their actual writings or blog posts, but was not evident in the feedbacks themselves.

None of the feedback was categorized within the application level, yet, it is important to note that each post required some sort of knowledge application to complete the tasks. The post content themselves however, did not demonstrate application.

\section{Level 4: Analysis}

Within this study, this is the threshold where critical thinking is thought to begin. Analysis is the dissection of the elements of a given concept or topic. When a student is comparing, examining, explaining, relating, draw conclusions, or contrasting their actions they illustrate this level of cognitive functioning. One student commented under the discussion of cheating. He states;

I was in a little thing called Battle of the Ballparks and the \#1 ballpark lost to the \#24 ballpark. You are only allowed to vote once per matchup but all the other matchups had 63 thousand the one matchup had 99 thousand. I don't think a person would vote for one and skip the others. I think someone wanted them to win and voted about 3 thousand times. (sic)

Because he was drawing a conclusion about the results of this poll, his post was considered as analyzing the process of the polls. In this case, and others, his post was interest based. He was into sports, specifically into baseball. Therefore when his favorite ballpark did not win the contest, he was more inclined to determine the reasoning behind the results. Students are willing to analyze content or ideas when their own opinions or ideas are challenged.

Another example of analysis that illustrates this opinion verification includes a student's question of "Why is everybody talking about Harry Potter these days?" This question requires the analysis of current children's literature and the distinguishing factors that allow this character to be popular. He is posing this question for an explanation of this character's popularity which contrasts with his opinion that this character is not worth discussing. Analysis was indicated in $4.8 \%$ or 6 out of 125 comments in the online feedback. Analysis was present $17.5 \%$ of the time or 10 out of 57 in the offline feedback.

\section{Level 5: Evaluation}

In this level, students are criticizing, critiquing, defending, supporting, or justifying when they are demonstrating within this point in the cognitive hierarchy. As the data were being analyzed, many occurrences in the Kidblog and Storybird feedback illustrated comments such as "This is awesome" or "This was a cool story." If those comments were followed with specific examples and justified reasons, they were categorized in level 5 . However, it is important to note that many stopped at those simple opinion statements and were categorized in the social media section due to their simple identification with use of broad statements. This type of commenting could not be categorized within Bloom's Taxonomy. 
In one student's critique rubric, she stated that the writer needed to "say how she feels when she was banned....express how she feels a bit more." This critic identified an improvement that could be made in the writing and made the judgment on what suggestions would lend to improving the paper by having the reader be more sympathetic to the villain. Another example that demonstrates evaluation emerged in the StoryBird feedback. The commenter wrote about a story that was created saying "Funny story, but I don't think the first one [slide] goes with the rest of the story" She made a critique on the story of it having a humorous tone and even commented on a slide of the story that was not a cohesive aspect with the rest of the story.

The nature of data lent itself to this category. The rubric was designed to produce comments that were critiquing or making judgments about the work. One criteria of the rubric was to determine if the writer achieved the goal of "using appropriate voice and tone in the writing." This teacherdesigned guideline encouraged responses that were evaluative resulting in a massive amount of the data for this feedback at level 6 . However, within the social media, the response criteria were student guided and determined. Because a minimum amount of the social media was found at this level, we determined that unless students are guided or expected to produce evaluative comments, they do not initiate this type of commenting when reviewing their peer's works.

Within this uppermost tier of the taxonomy, the social media feedback was demonstrated 27 times or $21.6 \%$ where $61.4 \%$ of all responses with a raw number of 35 in the offline critique were seen as making judgments within the evaluation level.

\section{Level 6: Synthesis}

Whether synthesis derives from an original place or as an improvement upon an existing element, the goal is to create. Actions in the classroom that identify where synthesis is occurring include activities where they are composing, creating, and revising. When analyzing the feedback in all forms, the data were categorized not only as the cognitive level of the actual response, but of what the response was asking of the writer. Within the peer critiques of the Villain projects, examples emerge where the critic was asking the author to revise on a synthesis level. So, even though the actual comment, "Instead of writing about the torchering(sic) of Emma's parent first maybe, you should write about her giving her to the school nurse," falls under the evaluation category, what it asks the writer to do is considered synthesis. The reviewer is asking the writer to modify the structure of her writing and rewrite this part to create a more cohesive paper. So, even though the post itself is categorized under level 6 , what the feedback is asking of the writer is considered synthesis. This finding suggests that within the writing process, synthesis and evaluation are connected.

Another example of how synthesis arose in the feedback was when the students blogged as their villains from their writing project or a supporting character in a story. The creative writers had to understand their character and create posts that demonstrated the character's perspective. One student wrote "Victory is awesome! But living in the Capitol already is a victory, and being as rich and good looking as a guy like me." In her post, she took on the persona of Caesar Flickerman from The Hunger Games written by Suzanne Collins. The character in the book has a positive 
perspective and she appropriately responded to a comment by keeping it positive as he probably would have done.

Any type of formal writing requires this level of critical thinking because the writer is composing in an original form, revising it along the way. Sometimes the modifying originates from the writers themselves, other time it stems from an alternate source, like peers. Analysis, which is considered to be the initial level of critical thinking, showed 10 times or $8 \%$ in the social media, but was not evident in the rubrics. However, in 19 of the 35 or $54.2 \%$ of evaluation (level 5) incidences within the rubric, the critiques required the author to create, rewrite, or reconstruct their writings in some way which would be considered within level five or synthesis level. The rubric asked the peer reviewer to critique the author's work based on certain writing goals by requiring them to discuss if the goals were met, then justify why the reviewer believed so. These comments were categorized under level 5; however, the reviewers were also required to make suggestions to improve each goal in the rubric. Synthesis was present in the actions the author had to make to revise the paper based on the critique of the reviewer. Because of only categorizing each response in one category though, none of them were labeled under level6.

\section{Social Media Lingo}

Not all data were fittingly categorized within the parameter of Bloom's Taxonomy of cognitive functioning. Occurring very often within social media contents, students often wrote very vague opinion comments that did not reflect a true conceptualization of their ideas. These examples include comments such as "This was a cool story," "Can't believe it," and "This is awesome." None of these comments supply criteria that formed their opinions or provide any sort of reasoning; therefore, these types of comments are considered as a pre-category level that exists before the hierarchy. This level, entitled Social Media appeared in the online contexts much more than the teacher guided peer rubric. In $24.8 \%$ of posts, these types of commenting were present as opposed to $1.7 \%$ occurrences in the critique rubric. There were 31 comments in the online feedback that were categorized as this informal lingo.

Students take on an informal role of language within this social media lingo. They write as if they were texting the writer or posting a comment on Facebook instead of responding within the formal contexts of the online writing space. They use incomplete sentences and simple expressions of feelings. We found that in the data there were cross-overs of this lingo that were used in the social settings and in the academic commenting spaces. The hesitance of publishing anything too in depth might be due to the social perception that critiquing a piece of writing (without the teacher's insistence) has a negative connotation or that they are actually criticizing the work or the writer themselves. To neutralize these fears, the reviewer should give positive feedback first. This will lower the initial anxiety and allow for easier acceptance of negative feedback (Topping, 2009).

If considering that the sub level of social media and the levels 1-3 of Bloom's Taxonomy do not require critical thinking, $64 \%$ of the posts and $21 \%$ of the rubric comments did not demonstrate any form of critical thinking. In contrast, levels 4-6 do require some sort of critical thinking, 
whether in the comment itself or in what the comment requires of the author. The online posts demonstrated this in $23.2 \%$ of comments and the peer rubrics $78.9 \%$ of comments (See Figure 1 ).

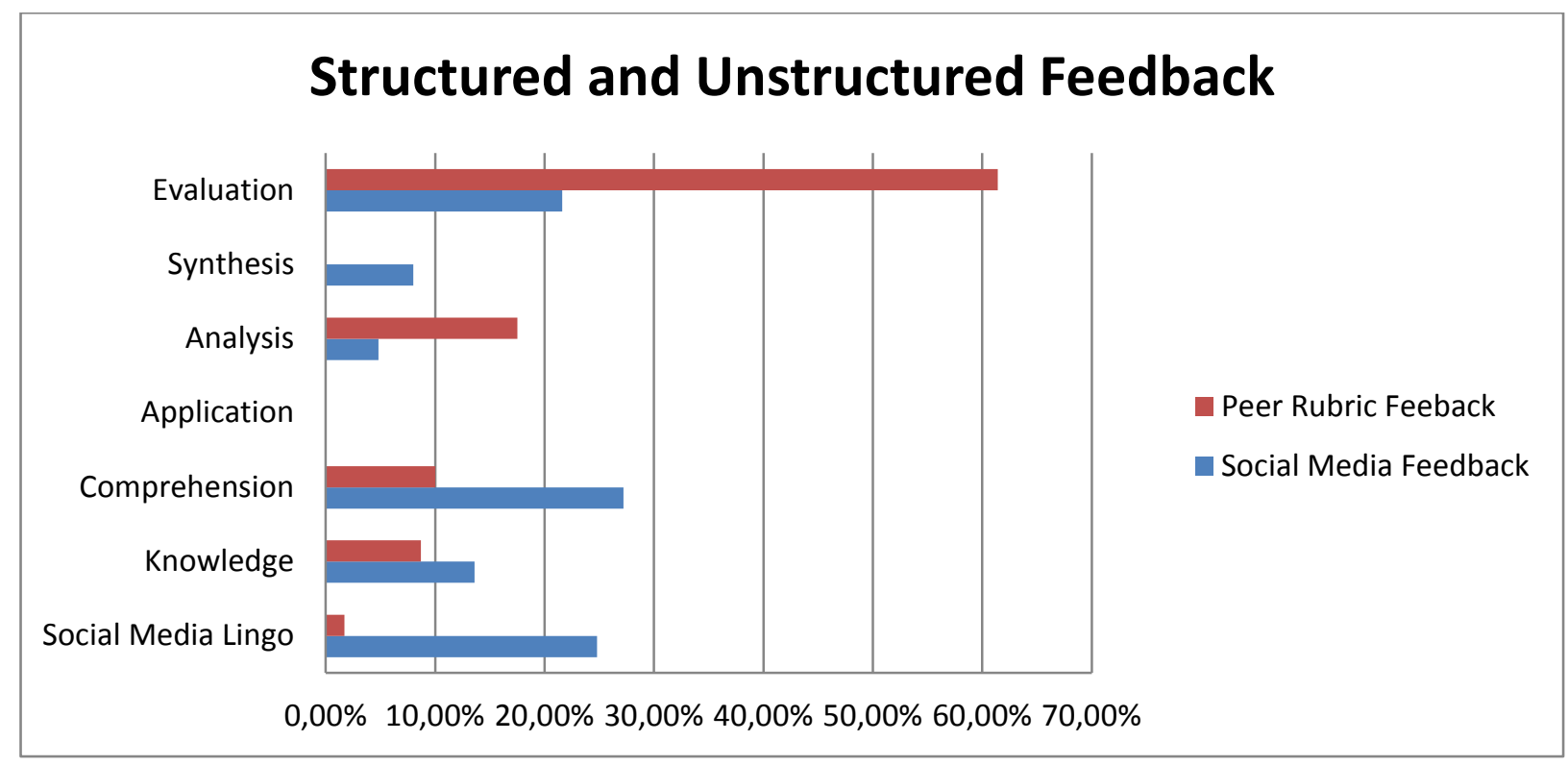

Figure 1. Percentage of Bloom's Taxonomy levels found in both the offline and online feedback

\section{Discussion}

Critical thinking activities and educational technology integration for gifted students are important in the gifted classroom because they allow students to become active participants in their program of study (Smutney, 2011). Social media feedback is a tool to be utilized within the classroom because these interactions allow for opportunities of ideas to be validated and students' writings to be analyzed and evaluated for improvement purposes. The vast amount of learning occurs in social negotiations, not necessarily by being directly taught (Jonassen, Carr, \& Yueh, 1998). Students learn through the interactive process of peer commenting and relations. Therefore, the implementation of these activities in the gifted classroom provide opportunities for critical thinking in the social media peer feedback forum.

An interesting observation emerged in categorizing and analyzing the data. Students in the blogging realm represent themselves in their social dialogue more so than an assumed classroom discussion or by paper and pencil in the classroom where the students' expectations are preset. This informal writing style was present in the blogs and Storybird feedback, yet it was nearly absent in the teacher guided peer critique rubric. This may be due to that the rubric feedback was guided by goals that were written on the rubric itself. For example, the rubric asked for evaluations of organization, tone, and creative writing. This provided the students with a reference to guide appropriate responses and encouraged responses that are in the upper tiers of Bloom's Taxonomy. However, on the social media feedbacks, even though the teacher commented on the 
Smithsonian posts, this guidance was not pre-taught or within the requirements of the post. Students may be accustomed to providing evaluative feedback on paper from their school experiences. Gifted children show an ability to understand and answer high level questions when provided with a teacher rubric.

One explanation of the fact that gifted students showed more critical thinking in the offline feedback is that many social interactions occur within the educational technology realm and students are not effective in separating the expectations in these online environments. In fact, Rideout, Foehr, and Roberts (2010) indicated that $40 \%$ of adolescents will visit a social networking site in a day and spend an average of almost an hour there. Students' perceptions of their expectations in these social media environments are similar to those informal occurrences outside of multi-media experiences, such as on the playground or in the lunch room. This is true even on teacher assigned social networks. It is noted that students used slang in their feedback such as 'dude,' 'rock on,' 'haha,' 'idk,' and the common "-)." These types of commenting are common within their verbal communications and other educational media like texting or emails. Another noticeably social media concern beyond the slang was that it was quite common in the students' feedback posts online to exaggerate in their posts. Examples include multiple exclamation marks, "He shall be DOOMED!!!!" or "guilty!!!!!!!!!!!!!!!!!!!!!!!" and the spelling of words, "Oh noo000000000000000000" and "Whhhhyyyyyyy?????????????." Occurrences of exaggerating using punctuation or spelling and using educational technology slang were rarely noted in their writing or the teacher-guided, peer critique rubric. This indicated that even though these projects were completed on the computer, it is not the educational technology itself that promotes this social dialogue, but by how students perceive these online spaces. Students still demonstrated proper writing 'etiquette' within the writing forums of the peer critique and their writing projects, yet the slang and exaggerations were present consistently in the social media forums.

There are positive aspects to the social media lingo, though. This type of language is within the comfort realm of the students. Outside of teacher direction or even academic settings, this is how the students communicate. Therefore, integrating this lingo in the academic educational technology classroom may prove as a bridge between the two worlds of education and social. Prensky (2001) has noted that a major problem in education is the communication gap between the digital natives and their digital immigrant teachers. Their languages are vastly different. Providing online forums where students can utilize their digital language as well as meet teacher criteria helps connect the immigrant and native cultures. However, the teacher would have to provide the criteria for when and to what extent it can be utilized within curriculum.

Feedback on the computer is seen as informal, thus producing such social dialect. Within the workshop, the parameters of appropriate feedback were not addressed, it was assumed. Therefore, there was little direct instruction or guidelines on feedback expectations. However, the data has indicated a need for such guidance indicating that only $34.4 \%$ of the online peer commenting led itself toward critical thinking. Keh (1990) suggests that students tend to focus on lower-order feedback that encompass comments on grammar or comments such as "Great" He also suggest to have students focus on higher order commenting (termed in this article critical thinking), there needs to be teacher management for effective feedback to occur. In other words, for feedback to be effective and useful within the classroom, direct instruction on how to utilize these online feedback forums and what is acceptable as a response should be a precursor to the 
activity. Therefore, a teacher might want to provide an example of how they would like the feedback to be completed especially if their goal is to provide opportunities for critical thinking. For example, if students are to comment on another student's website, they need to be able to justify and defend their opinions or suggestions. Instead of the student just typing "I liked your story," some sort evidence or criteria needs to be included to support their broad statement. This can be achieved by the student giving specific examples like this one from the peer rubrics, "I liked your organization because I can see the picture coming into my head." A study by Ertmer et al., (2007) showed that there was no significant difference between teacher or peer online comments in improving posting content, suggesting that once effective strategies have been established in the classroom, media peer feedback can be an effective tool in the critical thinking process.

In essence, these findings mirror other scholars' conclusions that the emphasis is actually not on the educational technology (Drexler, Dawson, and Ferdig, 2007; Vie, 2008) ; the educational technology serves as a tool that can motivate students and improve their writing only because of the relationships and experiences the children and teachers share. Simply utilizing peer commenting features does not improve reflection (Chen, Wei, Wu, \& Uden, 2009) nor motivation.

\section{Implications}

The practical implications of this study center on the need to provide high expectations, modeling, and social supports for children using technology in their writing. Even students identified as gifted learners benefit from guiding questions which set an expectation for critical thinking. Students need to learn the levels of Bloom's Taxonomy and receive praise and credit for using the higher levels in their online peer feedback. This includes the need to support opinions with evidence from the writings. While there were no instances of overly critical feedback, it is helpful for teachers to use sites like storybird and kidblog that allow for comment moderation. Not only can comment moderation be used to scan for offensive comments, but it can be used to encourage children to use feedback features to workshop stories rather than to engage in informal chatter. Teachers can build a supportive community in the classroom where students understand that constructive feedback is not negative. Teachers can ask students to post two positive comments and one suggestion, so that there is not an overabundance of suggestions. Teachers can also teach students that the author gets to choose which suggestions they incorporate into their final draft. This technique allows authors to retain control over their work while still making revisions. Social media can be a valuable writing intervention, but only if students and teachers work together to make online social environment that is both social and academically-oriented.

Acknowledgement: This research reported in this article was funded by a West Virginia University Program Evaluation and Research Center (PERC) grant.

\section{References}

Baxter, P. \& S. Jack. (2008). Qualitative case study methodology: Study design and implementation for novice researchers. The Qualitative Report, 13(4), 544-559. 
Bloom, B. S., Engelhart, M. D., Furst, E. J., Hill, W. H., \& Krathwohl, D. R. (1956). Taxonomy of educational objectives: Handbook I: Cognitive domain. New York: David McKay, 19, 56.

Bran, R. (2010). Message in a bottle Telling stories in a digital world. Procedia-Social and Behavioral Sciences , 2 (2), 1790-1793.

Chen, N., Wei, C., Wu, K., \& Uden, L. (2009). Effects of high level prompts and peer assessment on online learners' reflection levels. Computers \& Education , 52 (2), 283-291.

Ertmer, P. A., Richardson, J. C., Belland, B., Camin, D., Connolly, P., Coulthard, G., Lei, K., \& Mong, C. (2007).Using peer feedback to enhance the quality of student online postings: An exploratory study. Journal of Computer-Mediated Communication, 12(2), 412-433.

Flower, L., Hayes, J., Carey, L., Schriver, K., \&Stratman, J. (1986).Detection, diagnosis, and the strategies of revision. College Composition and Communication, 37(1), 16-55.

Gay, L. R., Mills, G. E., \&Airasian, P., (2012). Educational research: Competencies for analysis and applications $\left(10^{\text {th }}\right.$ ed.). Upper Saddle River, NJ: Pearson Education.

Graham, S., McKeown, D., Kiuhara, S., \& Harris, K. (2012).A meta-analysis of writing instruction for students in the elementary grades. Journal of Educational Psychology, No pagination specified.

Halpern, D. F. (1998).Teaching critical thinking for transfer across domains: Dispositions, skills, structure training, and metacognitive monitoring. American Psychologist, 53(4), 449-55.

Jonassen, D., Carr, C., \& Yueh, H. (1998).Computers as mindtools for engaging learners in critical thinking. TechTrends, 43(2), 24-32.

Katsarou, E. (2009). A multiliteracy intervention in a contemporary "mono-literacy" school in Greece. International journal of learning, 16(5), 55-65.

Kaufman, J. C., Gentile, C. A., \& Baer, J. (2005). Do gifted student writers and creative writing experts rate creativity the same way?. Gifted Child Quarterly, 49(3), 260-270.

Keh, C. L. (1990). Feedback in the writing process: A model and methods for implementation. ELT Journal, 44(4), 294-304.

MacArthur, C., Schwartz, S., \& Graham, S. (1991). Effects of a reciprocal peer revision strategy in special education classrooms. Learning Disabilities Research \& Practice. 6(4), 201-210.

New London Group. A pedagogy of multiliteracies: Designing social futures. (1996). Harvard Educational Review, 66(1), 60-92.

Olthouse, J. M. \& Miller, M. T. (2012). Teaching talented writers with Web 2.0 tools. Teaching Exceptional Children, 45(2), 6-14.

Patchan, M. (2011). Peer review of writing: Learning from revision using peer feedback and reviewing peers' texts (Unpublished doctoral dissertation). University of Pittsburgh. Pittsburgh, Pennsylvania.

Patton, M. Q. (2002). Qualitative evaluation and research methods (3rd ed.). Thousand Oaks, CA: Sage.

Piirto, J. (1992). Understanding those who create. Dayton, OH. Ohio Psychology Press. 
Prensky, M. (2001) Digital natives, digital immigrants. On the Horizon. 9(5), 1-6.

Rideout, V., Foehr, U., \& Roberts, D. 2010. Generation M2: Media in the lives of 8 to 18 year olds. Kaiser Family Foundation. Menlo Park, California.

Shoffner, M., De Oliveira, L. C., \& Angus, R. (2010). Multiliteracies in the secondary English classroom: Becoming literate in the 21st century. English Teaching: Practice and Critique 9(3), 75-89.

Smutny, J. (2011). Challenge your top students. Instructor, 121(3), 30-35.

Stoddard, B. \& MacArthur, C. (1993). A peer editor strategy: Guiding learning-disabled students in response and revision. Research in the Teaching of English, 27(1), 76-103.

Topping, K. J. (2009). Peer assessment. Theory into Practice, 48(1), 20-27.

Vie, S. (2008). Digital divide 2.0: "Generation M" and online social networking sites in the composition classroom. Computers and Composition , 25 (1), 9-23.

Vincent, J. (2006). Children writing: Multimodality and assessment in the writing classroom.

Literacy, 40(1), 51--57.

Yagelski, R. (1995). The role of classroom context in the revision strategies of student writers. Research in the Teaching of English, 29(2), 216-238.

Yang, Y. (2012). Multimodal Composing in Digital Storytelling. Computers and Composition , 29(3), 221--238.

Yarrow, F. \& Topping, K. J. (2001). Collaborative writing: The effects of metacognitive prompting and structured peer interaction. British Journal of Educational Psychology, 71(2), 261-282.

Correspondence: Myriah T. Miller, Department of Special Education, West Virginia University, Morgantown, West Virginia, United States 